\title{
PROTOCORMS OF AN EPIPHYTIC ORCHID (EPIDENDRUM AMPHISTOMUM A. RICHARD) RECOVERED IN SITU, AND SUBSEQUENT IDENTIFICATION OF ASSOCIATED MYCORRHIZAL FUNGI USING MOLECULAR MARKERS
}

\author{
LAWRENCE W. ZETTLER ${ }^{1, *}$, LAURA L. COREY ${ }^{1}$, LARRY W. RICHARDSON $^{2}$, \\ APRIL Y. ROSS ${ }^{1,3}$, and LILLIAN MOLLER-JACOBS 1,4 \\ ${ }^{1}$ Department of Biology, Illinois College, 1101 West College Avenue, Jacksonville, IL 62650 USA \\ ${ }^{2}$ Florida Panther National Wildlife Refuge, U.S. Fish and Wildlife Service, 3860 Tollgate Boulevard, Suite 300, Naples, FL 34114, USA \\ ${ }^{3}$ Current address: Department of Public Heath, University of Illinois at Springfield, Springfield IL, 62703 USA \\ ${ }^{4}$ Current address: Department of Entomology, 501 ASI Building, Pennsylvania State University, University Park, PA 16802 USA \\ ${ }^{*}$ Corresponding author: lwzettle@ic.edu; Tel.: (217) 245-3479; Fax: (217) 245-3358
}

\section{ABSTRACT}

Epiphytic orchids have received considerable study, yet little has been published on their germination requirements in situ involving mycorrhizal fungi. Such research has been hampered by the small, dust-like size of seeds and leafless seedlings (protocorms) which are difficult to pinpoint on natural substrates, especially those on arboreal substrates (tree limbs). We report a novel seed sowing and retrieval method, modified from one applied to terrestrial orchids, used in the acquisition of epiphytic orchid protocorms from the Florida Panther National Wildlife Refuge. Seeds from two epiphytic orchid species (Epidendrum amphistomum A. Richard, E. nocturnum Jacquin) were placed in separate nylon mesh packets secured within $35 \mathrm{~mm}$ plastic slide mounts, and affixed to tree bark using gutter mesh and a staple gun. To confirm that the embryos were viable, some seeds were also sown on asymbiotic media in the laboratory which subsequently germinated after 52 days incubation. Of 60 packets distributed among 18 tree limb sites, one packet - harboring seeds of $E$. amphistomum affixed to pop ash (Fraxinus caroliniana Mill.) on a moss substrate - harbored protocorms after 267 days. Using molecular markers, a fungus assignable to the Ceratobasidiaceae, appears to be the mycorrhizal associate of these protocorms suggesting that this fungus may be associated with the germination process in situ.

Keywords: symbiotic germination, seed baiting, South Florida, seedlings

\section{Introduction}

Orchids have received considerable study especially their taxonomy, pollination mechanisms, and cultivation, but relatively little has been published on their germination requirements in situ involving mycorrhizal fungi. Although terrestrial orchids have received the most attention in this regard (e.g., Rasmussen 1995; Brundrett et al. 2003; Batty et al. 2006), tropical epiphytic taxa - which comprise ca. $73 \%$ of the $17,000-35,000$ species worldwide (Atwood 1986; Dressler 1993) - remain understudied, especially with respect to their obligate mycorrhizal relationships (Otero et al. 2007). Recently, a growing number of studies aimed at identifying mycorrhizal associates of epiphytic orchids have surfaced worldwide facilitated by DNA and TEM methods (e.g., Ma et al. 2003; Martos et al. 2009; Roy et al. 2009; Herrera et al. 2010; Kottke et al. 2010; see review by Dearnaley et al. 2012). In light of ongoing habitat destruction, especially in the biologically diverse tropics, additional studies are urgently needed to augment conservation of this unique plant family.

Tremblay et al. (1998) noted that certain epiphytic orchids are associated with a particular tree species, and Rasmussen (2002) proposed that this phenomenon may be linked to the tree serving as a suitable host for the orchid's mycorrhizal fungi. Similarly, Gowland et al. (2011) hypothesized that some epiphytic orchids may be associated with a specific host tree species because they demonstrate a bias for certain types of mycorrhizal fungi associated with the host tree's substrate, and that this bias develops early in the orchid's life. Yoder et al. (2000) demonstrated that leafless epiphytic orchid seedlings (protocorms) have lower water loss rates compared to asymbiotically-grown seedlings, and proposed that mycotrophy serves as a critical water source for small seedlings of arboreal substrates vulnerable to desiccation. To more fully ascertain the role of mycorrhizal fungi on epiphytic orchid distribution and physiology, locating and recovering protocorms in situ is clearly desirable, but extremely difficult due to their minute size (ca. 1-10 mm). The use of a seed sowing and recovery technique devised by Rasmussen and Whigham (1993; see $\mathrm{H}$. Rasmussen this volume) has contributed to our understanding of germination requirements of terrestrial orchids in soil (e.g., Rasmussen and Whigham 1998), but to our knowledge this technique has yet to be successfully applied to the epiphytes, possibly due to difficulties attributed to substrate accessibility (e.g., tree limbs).

In south Florida, most of North America's native epiphytic orchids are restricted to the Big Cypress Basin eco-region in habitats (e.g., cypress domes, sloughs) sheltered from subfreezing temperatures (Brown 2005). Many of these epiphytes are rooted on limbs of smaller (ca. 10-15 m) understory trees that are accessible by foot and/or boat, making long-term in situ observations possible. In this study, we report our preliminary results 
aimed at acquiring protocorms of two North American Epidendrum species within the Florida Panther National Wildlife Refuge using Rasmussen and Whigham's (1993) technique subsequently modified for arboreal substrates. The identity of the mycorrhizal fungi acquired from protocorms captured in this manner is also described using Random Amplification of Polymorphic DNA (RAPD) analysis.

\section{Materials and Methods}

\section{Study site}

Seeds were acquired from two epiphytic orchid species that grew naturally within the Florida Panther National Wildlife Refuge in Collier Co., FL; Epidendrum amphistomum A. Richard (Fig. 1), and Epidendrum nocturnum Jacquin. These donor plants were located in the same habitat where seed sowing was carried out. The habitat consisted of an oft-flooded cypress dome measuring ca. $300 \mathrm{~m} \times 200 \mathrm{~m}$, dominated by mature bald cypress, Taxodium distichum (L.) L. C. Rich. Epiphytic orchids were affixed primarily to understory trees, namely pop ash (Fraxinus caroliniana Mill.), pond apple (Annona glabra L.), and red maple (Acer rubrum L.). In addition to E. amphistomum and E. nocturnum, eight other epiphytic orchid taxa were present at the site: Campylocentrum pachyrrhizum (Reich. f.) Rolfe, Dendrophylax lindenii (Lindl.) Bentham ex Rolfe, Epidendrum floridense Hág-

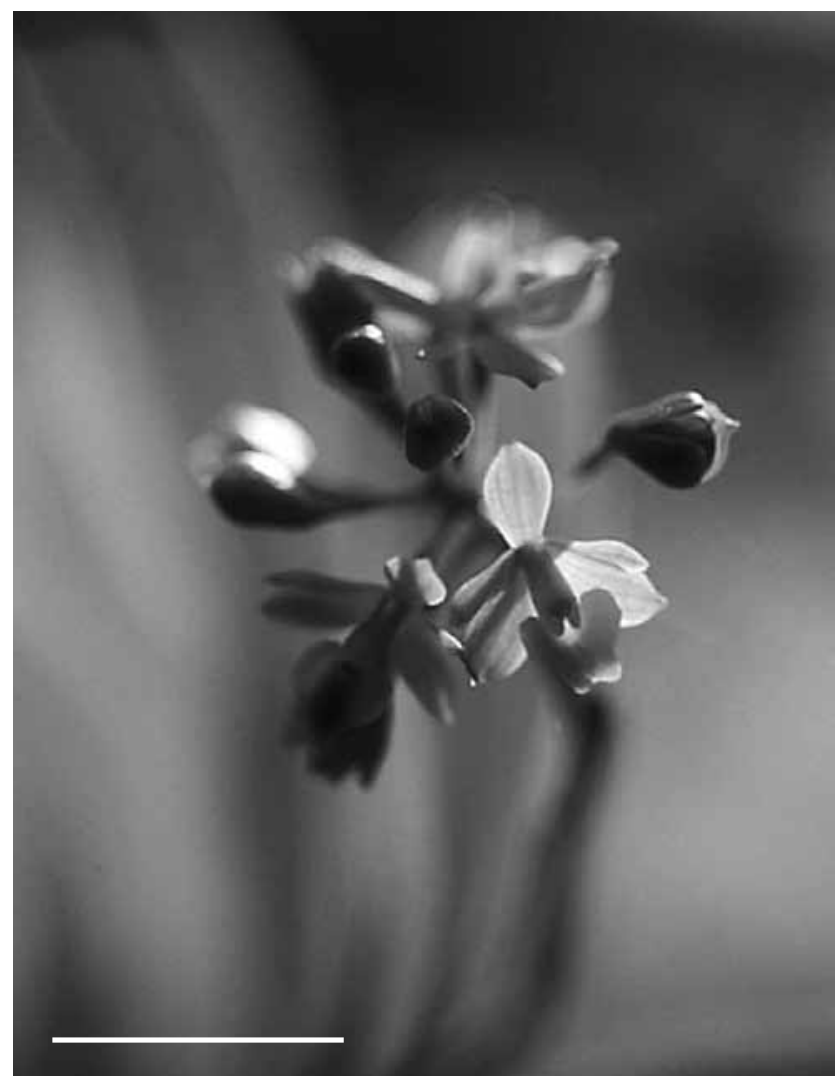

Fig. 1 Epidendrum amphistomum in flower. Scale bar $=3 \mathrm{~cm}$. sater, E. rigidum Jacquin, Ionopsis utricularioides (Swartz) Lindl., Polystachya concreata (Jacquin) Garay and Sweet, Prosthechea boothiana (Lindl.) Higgins var. erythronioides (Small) Higgins, P. cochleata (L.) Higgins var. triandrum (Ames) Higgins. Various growth stages of epiphytic orchids, including seedlings and juveniles, were commonplace on limbs of the understory trees, especially in association with mosses.

\section{Seed collection, sowing and retrieval}

To mimic natural conditions as much as possible, mature capsules in the act of dehiscing were obtained as a seed source. Capsules - one from E. amphistomum and two from E. nocturnum (designated EA, and $\mathrm{EN}_{1}$, $\mathrm{EN}_{2}$, respectively) were detached from inflorescences on 29 May 2009, placed separately in sealed plastic bags, and immediately taken to a laboratory located on site at the FPNWR. By gently tapping each capsule, ca. 500-1000 seeds were added to the surface of nylon sifting material (95 $\mu \mathrm{m}$ pre size, \#65-2222M, Carolina Biological Supply Co., Burlington NC, USA) measuring $5 \mathrm{~cm} \times 5 \mathrm{~cm}$. A seed-containing packet was constructed by folding the square and inserting it into a $35 \mathrm{~mm}$ plastic Polaroid photographic slide mount (Sigma-Aldrich Co., St. Louis, MO, USA), following the procedure by Rasmussen and Whigham (1993). To firmly secure each square within the slide mount, the frame was stapled on all four sides. On one side of the frame, the seed source (e.g., $\mathrm{EN}_{1}$ ), date (30 May 2009), site location (1-18), substrate type ( $\mathrm{B}=$ exposed bark, $\mathrm{M}=$ lichen, $\mathrm{M}=$ moss), and substrate tree $(\mathrm{PA}=$ pop ash, $\mathrm{RM}=$ red maple) were recorded using a permanent marking pen (Sharpie ${ }^{\circledast}$, Sanford Corp., Oak Brook, IL, USA). A total of 20 packets were constructed for each of the three seed sources. Three packets (one from each seed source) were then affixed to tree limbs at 18 different site locations within the study area. Each location was separated by a minimum of $5 \mathrm{~m}$, and on a different tree limb or tree within the study area. Locations were chosen based on their accessibility by foot or boat, and on the quantity of the substrate type available (exposed bark, moss, lichen). Substrate types were designated accordingly if $>90 \%$ of the surface was uniform (e.g., "moss" substrate type $=90 \%$ or more of the surface was covered by living moss). Lichen substrates consisted almost entirely of Chiodecton spp. Sites 1-4, 5-8, and 9-12 harbored bark, moss, and lichen substrates on pop ash (PA), respectively. Sites $13-14,15-16,17-18$ consisted of bark, moss and lichen substrates on red maple (RM), respectively. A plastic gutter mesh square $(20 \mathrm{~cm} \times$ $20 \mathrm{~cm}$ ) and a staple gun were used to affix the three packets as a cluster to each tree limb (Fig. 2). The side of each packet containing the information written by Sharpie ${ }^{\odot}$ was oriented to face the substrate to reduce the likelihood that this information would fade upon exposure to sunlight. On 24 July 2009, selected packets were lifted from the gutter mesh and inspected on site for germination. 


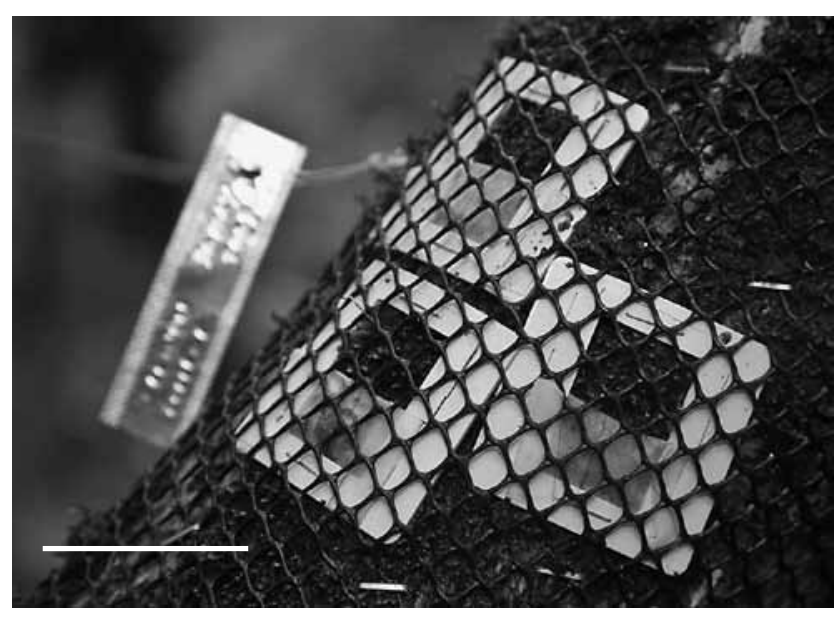

Fig. 2 A cluster of three seed packets affixed to a tree branch with gutter mesh. A staple gun was used to deliver staples permitting packets to remain in continuous close contact with the substrate. Scale bar $=5 \mathrm{~cm}$

This was facilitated visually using a hand lens, and did not require packets to be opened. Immediately after inspection, packets were returned to the gutter mesh/substrate interface.

To verify that seeds from the three sources $\left(\mathrm{EA}, \mathrm{EN}_{1}\right.$, $\mathrm{EN}_{2}$ ) were viable, a subset of each source was sown on asymbiotic media (P723, PhytoTechnology Laboratories, Shawnee Mission, KS, USA) on 9 June 2009, using standard protocols (e.g., Stewart and Kane 2006). Five replicate plates were prepared for each seed source, and plates were incubated at ambient temperature (ca. $20^{\circ} \mathrm{C}$ ) under artificial illumination (irradiance measured at $\left.80 \mu \mathrm{mol} \mathrm{m} \mathrm{m}^{2} \mathrm{~s}^{-1}\right)$. Within 52 days, seed germination (= rupture of testa by enlarged embryo) was evident in vitro among all three sources, confirming their viability.

On 20-21 February 2010, all seed packets were detached from tree limbs at the 18 sites and immediately taken to the FPNWR laboratory where the contents were opened and photographed. Packets that contained protocorms were gently placed in aseptic plastic bags, sealed, and promptly ( $<1$ week) returned to Illinois College for molecular characterization.

\section{Molecular characterization}

Two strains of Rhizoctonia-like fungi (Ceratobasidiaceae, Tulasnellaceae) were utilized for comparative purposes involving molecular techniques, and were chosen because both are common, ubiquitous mycorrhizal associates of epiphytic and terrestrial orchids worldwide (Zettler et al. 2003). The strain assignable to the Ceratobasidiaceae (Pleu-263) originated from a root peloton of Platanthera leucophaea (Nutt.) Lindl. from a prairie remnant in Monroe Co., Michigan (Zettler et al. 2001), whereas the other strain (Tulasnellaceae, Pi-70) was acquired from a root peloton of $P$. integrilabia (Correll) Luer in Greenville Co., South Carolina (Zettler and McInnis 1992). The latter fungus was deposited into the University of Alberta (Canada) Microfungus Collection and Herbarium as UAMH 7632.

DNA was isolated from fungal strains, asymbiotic plants, and protocorms recovered in situ using the Omega EZNA Plant DNA kit protocol for fresh/frozen samples (Omega Biotek, Doraville, GA, USA). Random Amplification of Polymorphic DNA (RAPD) analysis was performed on the DNA isolates using eight primers selected from the University of British Columbia (UBC) Primer Set \#1 (Shan et al. 2002). The $20 \mu \mathrm{l}$ amplification reactions contained $0.4 \mathrm{mM}$ dNTPs, $10 \mathrm{mM}$ Tris- $\mathrm{HCl}$, $\mathrm{pH} 8.3,50 \mathrm{mM} \mathrm{KCl}, 1.5 \mathrm{mM} \mathrm{MgCl}_{2}, 0.001 \%$ gelatin, 1.25 units of Sigma RedTaq DNA polymerase, $50 \mathrm{ng}$ of the selected DNA sample and 1 pmol of each of the following UBC primers: $65,73,89,31,91,66,34$, and 71 . The amplification was performed in a Programmable Thermal Cycler (Labnet, Edison, NJ, USA) programmed for $45 \mathrm{cy}$ cles each consisting of $94{ }^{\circ} \mathrm{C}$ for 30 seconds, $38^{\circ} \mathrm{C}$ for 30 seconds, and $72{ }^{\circ} \mathrm{C}$ for 60 seconds. Amplification products were visualized by electrophoresis on $2 \%$ agarose gels containing $0.1 \mathrm{mg} / \mathrm{ml}$ ethidium bromide. Amplification of the ITS region was carried out using primers ITS1-OF and ITS4-OF (Taylor and McCormick 2007).

\section{Results and Discussion}

\section{Germination in situ}

Seeds from all three sources that were inspected initially (55 days after sowing) displayed no signs of germination; however, embryos appeared larger in size and

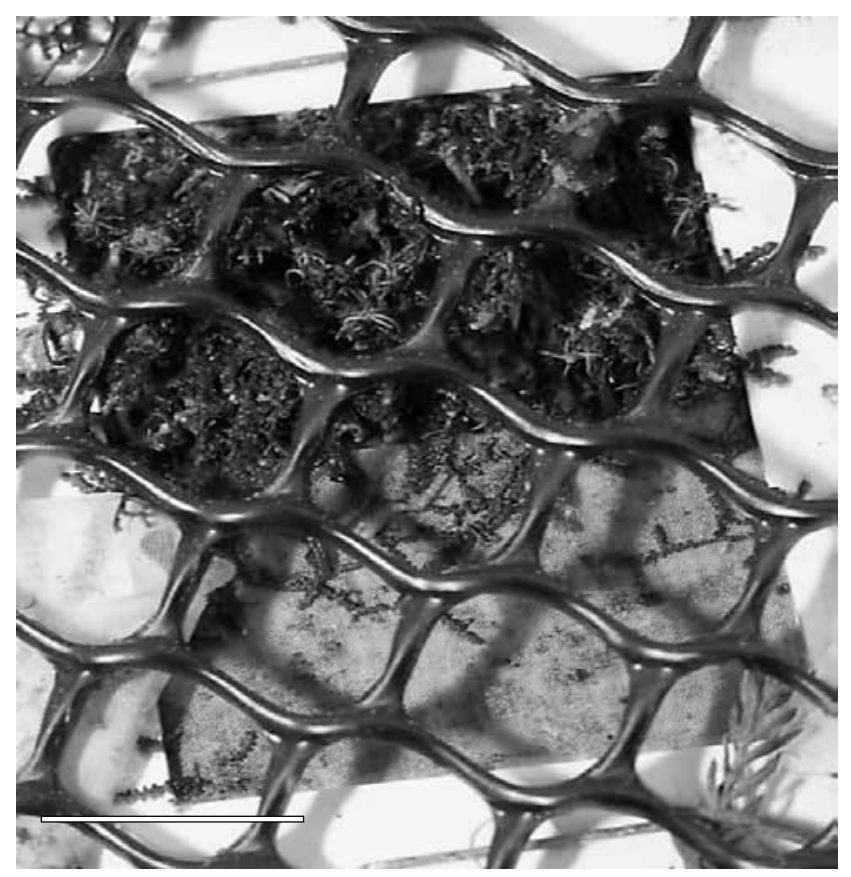

Fig. 3 Close up of seed packet beneath gutter mesh, 267 days after its attachment to a mossy substrate. Encroachment of leafy gametophytic tissue onto the packet and slide mount is clearly visible. Scale bar $=1 \mathrm{~cm}$ 


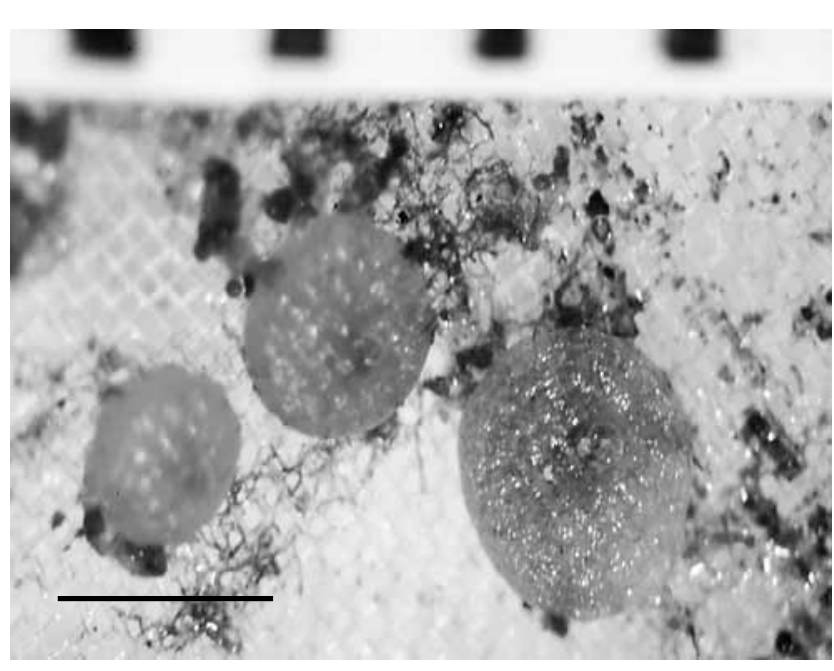

Fig. 4 Three protocorms of Epidendrum amphistomum visible within an opened seed packet after 267 days incubation in situ. The dark region in the center of each protocorm depicts the developing shoot as viewed from above. Scale bar $=1 \mathrm{~mm}$.

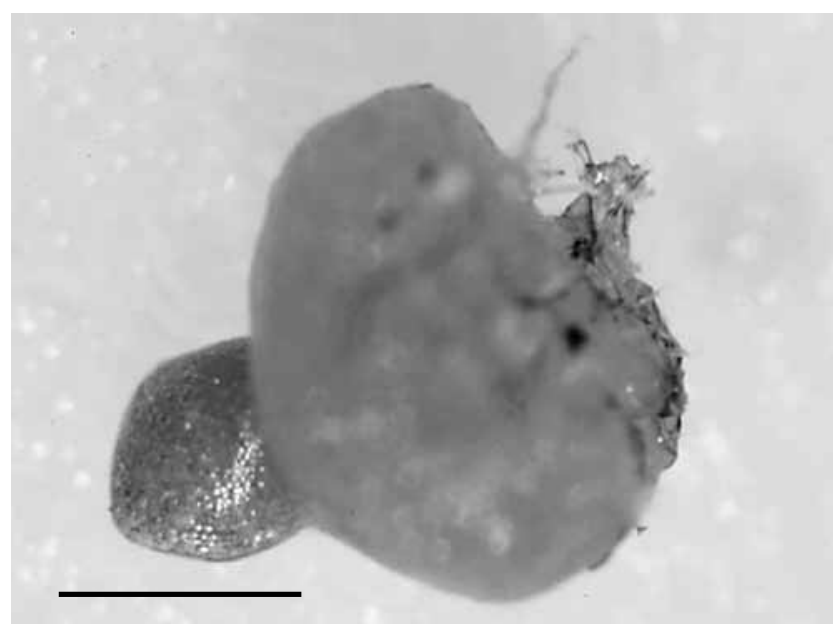

Fig. 5 Leaf-bearing protocorm of Epidendrum amphistomum viewed in side view after removal from seed packet. The emerging leaf is clearly evident, on the left. Scale bar $=1 \mathrm{~mm}$.

greener in color. In contrast, seeds sown in vitro to test viability germinated after 52 days indicating that development on asymbiotic media is more rapid in vitro than in situ. When the study was terminated after 267 days in situ, most of the packets that were placed on moss substrates were actively colonized by leafy mosses evident on the edges of the slide mount and packet (Fig. 3). Upon retrieval and subsequent inspection in the laboratory, only one of the 60 seed packets - acquired on a pop ash limb affixed to a moss substrate - harbored protocorms, and these were derived from E. amphistomum seed. A total of nine protocorms in various stages of development were recovered (Fig. 4 and 5). In the packets that lacked protocorms, only traces of seeds or seed residue were visible. Most of these packets also contained darkly pigmented fungal hyphae that appeared to have infiltrated the nylon mesh. Thus, it is conceivable that the seeds decomposed prior to packet retrieval.
To our knowledge, this is the first report documenting epiphytic orchid protocorms in situ using seed packets, and the first report that identifies the mycorrhizal fungi from this early growth stage. Although we acquired protocorms in this manner, this success rate appears to be low (1 of 60 packets, 1.7\%) compared to seed packets sown in soil for terrestrial orchids. For example, Masuhara and Katsuya (1994), recovered protocorms of Spiranthes sinensis var. amoena along 67 of 210 sampling points (32\%) after eight weeks, using cotton gauze instead of nylon. In Australia, Batty et al. (2001) reported germination in $14.2 \%$ of packets sown in a mediterranean bushland habitat containing seeds of Caladenia arenicola. Of 18 packets containing seeds of Platanthera holochila buried on Molokai (Hawaii), one packet (5.6\%) resulted in protocorms after a year in soil (L. W. Zettler, unpubl. data). This study, combined with these and others reported previously involving terrestrial orchids, supports the concept for spatial variability in orchid seedling recruitment within natural habitats (Batty et al. 2001; Rasmussen and Whigham 1998). As to why some orchid seeds germinate in packets placed in situ whereas others do not is probably attributed to a combination of intrinsic and extrinsic factors (e.g., seed dormancy, moisture availability; Baskin and Baskin 1998) that may vary depending on the species. For orchids - which additionally require mycorrhizal fungi that themselves have their own set of environmental needs - determining optimal seed germination conditions in situ poses a challenging task. Identifying the fungi associated with the germination process in situ represents a start.

\section{Mycorrhizal fungi}

RAPD amplification using the selected primers yielded distinct patterns for the cultured Ceratosidianceae strain, cultured Epulorhiza, and the asymbiotically-germinated E. amphistomum (Fig. 6). The pattern obtained from the E. amphistomum germinated in situ contains bands similar to both those observed in the asymbioticallygerminated E. amphistomum and those observed in the cultured Ceratosidianceae sample. This result suggests that the fungus present in E. amphistomum protocorms is assignable to Ceratosidianceae.

Based on the RAPD analysis, it appears that seeds of Epidendrum amphistomum utilized a fungus assignable to Ceratobasidium/Ceratorhiza to initiate germination and/ or protocorm development within the Florida Panther NWR. ITS amplification of the isolated DNA was conducted to parallel with the RAPD analysis using the PCR conditions and ITS primers described in Taylor and McCormick (2007). Insufficient PCR product was produced for successful sequencing. Ideally, the isolation of fungi from orchid tissues combined with use of molecular techniques would have been desirable, but the small number of protocorms acquired, combined with their small size, limited our options. Nevertheless, the possible link be- 


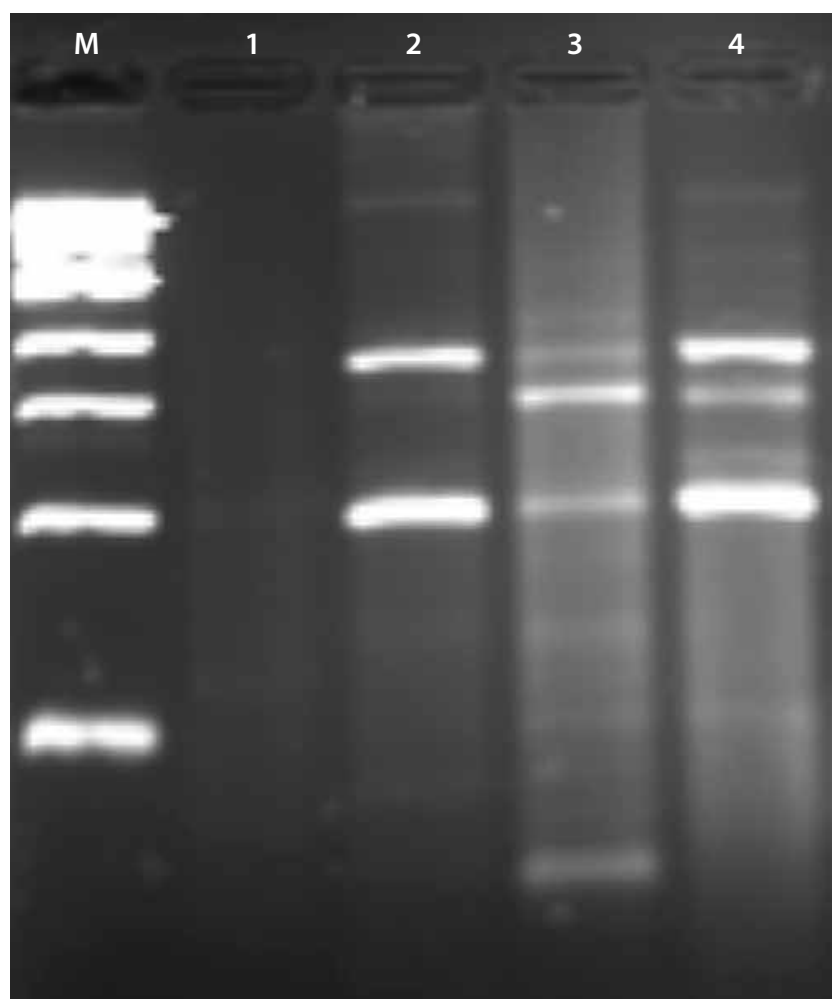

Fig. 6 Agarose gel showing products of RAPD amplification. $M=1 \mathrm{~kb}$ Markers (New England Biolabs). Lanes 1, 2, and 3 show amplification products from cultured Tulasnellaceae strain, cultured Ceratobasidiaceae strain, and asymbiotically germinated Epidendrum amphistomum, respectively. Lane 4 shows the amplification products obtained from the in situ seed packet containing E. amphistomum.

tween Ceratosidianceae with this orchid's early growth stage provides a first-time glimpse into the in situ seed germination needs of this epiphytic orchid.

Most of the mycorrhizal fungi that associate with epiphytic orchids worldwide (so far) have been assignable to the Ceratobasidiaceae, Tulasnellaceae and Sebacinales. Richardson et al. (1993), and Richardson and Currah (1995) reported that Epulorhiza (= Tulasnella/Sebacina) was less prevalent in Costa Rican epiphytic orchids; however, this genus was extensively isolated from two epiphytic orchids in Brazil (Pereira et al. 2003). In Puerto Rico, Costa Rica and Cuba, Porras-Alfaro and Bayman (2007) examined roots of terrestrial/epiphytic Vanilla spp. Using molecular sequencing (nrITS, mtLSU) and hyphal nuclear number, they revealed mycorrhizal fungi assignable to Ceratobasidium, Thanatephorus, and Tulasnella, and noted that Ceratobasidium was more common in roots from soil, whereas Tulasnella was more common in roots from tree bark. When some of these strains were tested for their potential to prompt in vitro seed germination, Ceratobasidium had a consistently positive effect on both germination and plant growth. In north Florida, Zettler et al. (1998) isolated an Epulorhiza strain (UAMH 9203) from roots of Epidendrum conopseum (= magnoliae), and used the fungus to cultivate seedlings to the leaf-bearing stage with seeds from the same host plant. In Brazil, Pereira et al. (2005) consistently isolated Epulorhiza epiphytica from roots of mature Epidendrum rigidium, and two strains (M1, M6) of Epulorhiza from E. rigidum and Polystachya concreta. Given that E. rigi$d u m$, and $P$. concreta occur naturally in both Brazil and south Florida, a unique opportunity awaits those that compare fungi acquired from these epiphytic orchid taxa spanning two hemispheres. Our use of the seed baiting technique may now make it possible for comparisons to be made involving protocorms as well as roots from mature plants.

\section{Suggestions for improvement}

In 2002, packets containing seeds of epiphytic orchids were suspended in slide mounts and affixed to tree bark in the Florida Panther NWR using thumb tacks, but this method failed to yield protocorms (S. L. Stewart, pers. comm.). In this study, slide mounts that were held firmly onto a moss substrate with gutter mesh (Fig. 2) resulted in germination in one packet, whereas those that were placed over lichens and exposed bark failed to yield protocorms. Using transects, Massey (2010) sampled 419 epiphytic orchids in FPNWR and reported that all naturally-occurring seedlings were associated with mosses, whereas juvenile and mature orchids were rooted on either mosses or a combination of moss and bark, primarily on pop ash. The combination of mosses on a tree species with notoriously spongy bark (pop ash) may provide a moisture-rich substrate conducive to fungal growth and proliferation, including those that trigger orchid seed germination. Yoder et al. (2010) reported that seeds of epiphytic orchids from the FPNWR (Epidendrum nocturnum, Encyclia tampensis) were smaller, more porous and had higher water loss rates compared to seeds of terrestrials. Taken together, the use of sterile, pre-moistened Sphagnum (peat) moss inserted into seed packets at the time of their construction may provide seeds with an additional and critical source of moisture that could potentially enhance this technique. Additionally, slide mounts are increasingly difficult to obtain. Possible alternatives include affixing the mesh seed packets directly to the gutter mesh, use of steel mesh rather than nylon mesh, and exploring other plastic products that are functionally equivalent to slide mounts. Efforts are underway to broaden this study using seed packets within the FPNWR and other sites in south Florida.

In these future experiments, molecular identification of the mycorrhizal fungi will be carried out using ITS amplification and sequencing following isolation and culture of pelotons. The RAPD protocol was originally chosen for this pilot study as a quick, simple, and inexpensive method to obtain a molecular identification from an indefinite number of samples. In retrospect, the resources and samples used to carry out this procedure would have been more profitably applied to ITS amplification and sequencing to provide a more exact identification. 


\section{Acknowledgements}

We graciously acknowledge the U.S. Fish and Wildlife Service, and Illinois College's Faculty-Student Research Committee for funding this research. We warmly thank James (JJ) Sadler and Jaclyn Smith for assistance with seed packet construction and field work. The technical support of Andrew Stice is also appreciated. Dr. Scott L. Stewart (Kankakee Community College, Illinois) provided helpful feedback.

\section{REFERENCES}

Attwood JT (1986) The size of the Orchidaceae and the systematic distribution of epiphytic orchids. Selbyana 9: 171-186.

Baskin CC, Baskin JM (1998) Seeds: ecology, biogeography and evolution of dormancy and germination. Academic Press, London.

Batty AL, Brundrett MC, Dixon KW, Sivasithamparam K (2006) In situ symbiotic seed germination and propagation of terrestrial orchid seedlings for establishment at field sites. Austral J Bot 54: 375-381.

Batty AL, Dixon KW, Brundrett M, Sivasithamparam K (2001) Constraints to symbiotic germination of terrestrial orchid seed in a mediterranean bushland. New Phytol 152: 511-520.

Brown PM (2005) Wild orchids of Florida. University Press of Florida.

Brundrett MC, Scade A, Batty AL, Dixon KW, Sivasithamparam K (2003) Development of in situ and ex situ seed baiting techniques to detect mycorrhizal fungi from terrestrial orchid habitats. Mycol Res 107: 1210-1220.

Dearnaley JDW, Martos F, Selosse M-A (2012) Orchid mycorrhizas: molecular ecology, physiology, evolution and conservation aspects. Fungal associations (2nd ed.), The Mycota IX. Hock B (ed) Springer-Verlag, Berlin Heidelberg (in press).

Dressler RL (1993) Phylogeny and classification of the orchid family. Dioscorides Press.

Gowland KM, Wood J, Clements MA, Nicotra AB (2011) Significant phorophyte (substrate) bias is not explained by fitness benefits in three epiphytic orchid species. Am J Bot 98(2): 197-206.

Herrera P, Suárez JP, Kottke I (2010) Orchids keep the ascomycetes outside: a highly diverse group of ascomycetes colonizing the velamen of epiphytic orchids from tropical mountain rainforest in Southern Ecuador. Mycology 1(4): 262-268.

Kottke I, Suárez JP, Herrera P, Cruz D, Bauer R, Huang I, Garcia S (2010) Atractiellomycetes belonging to the "rust" lineage (Pucciniomycotina) form mycorrhizae with terrestrial and epiphytic neotropical orchids. Proc Biol Sci 277: 1289-1298.

Ma M, Koon T, Wong SM (2003) Identification and molecular phylogeny of Epulorhiza isolates from tropical orchids. Mycol Res 107: 1041-1049.

Martos F, Dulormne M, Pailler T, Bonfante P, Faccio A, Fournel J, Dubois M-P, Selosse M-A (2009) Independent recruitment of saprotrophic fungi as mycorrhizal partners by tropical achlorophyllous orchids. New Phytol 184: 668-681.

Massey EE (2010) An undergraduate's first adventure into field research: an epiphytic orchid survey in southern Florida. N Am Native Orchid J 16(1): 31-37.

Masuhara G, Katsuya K (1994) In situ and in vitro specificity between Rhizoctonia spp. and Spiranthes sinensis (Persoon) Ames var. amoena (M. Bieberstein) Hara (Orchidaceae). New Phytol 127: 711-718.
McKendrick SL, Leake JR, Taylor DL, Read DJ (2002) Symbiotic germination and development of the myco-heterotrophic orchid Neottia nidu-savis in nature and its requirement for locally distributed Sebacina spp. New Phytol 154: 233-247.

Otero JT, Flanagan NS, Herre EA, Ackerman JD, Bayman P (2007) Widespread mycorrhizal specificity correlates to mycorrhizal function in the neotropical epiphytic orchid Ionopsis utriculariodes (Orchidaceae). Am J Bot 94: 1944-1950.

Pereira OL, Kasuya MCM, Borges AC, Fernandes de Araújo E (2005) Morphological and molecular characterization of mycorrhizal fungi isolated from neotropical orchids in Brazil. Can J Bot 83: 54-65.

Pereira OL, Rollemberg CL, Borges AC, Matsuoka K, Kasuya MCM (2003) Epulorhiza epiphytica sp. nov. isolated from mycorrhizal roots of epiphytic orchids in Brazil. Mycoscience 44: 153-155.

Porras-Alfaro A, Bayman P (2007) Mycorrhizal fungi of Vanilla: diversity, specificity and effects on seed germination and plant growth. Mycologia 99(4): 510-525.

Rasmussen HN (1995) Terrestrial orchids from seed to mycotrophic plant. Cambridge Univ Press.

Rasmussen HN (2002) Recent developments in the study of orchid mycorrhiza. Pl Soil 244: 149-163.

Rasmussen HN, Whigham DF (1993) Seed ecology of dust seeds in situ: a new study technique and its application to terrestrial orchids. Am J Bot 80: 1374-1378.

Rasmussen HN, Whigham DF (1998) Importance of woody debris in seed germination of Tipularia discolor (Orchidaceae). Am J Bot 85: 829-834.

Richardson KA, Currah RS (1995) The fungal community associated with the roots of some rainforest epiphytes of Costa Rica. Selbyana 16: 49-73.

Richardson KA, Currah RS, Hambleton S (1993) Basidiomycetous endophytes from the roots of neotropical epiphytic Orchidaceae. Lindleyana 8: 127-137.

Roy M, Watthana S, Stier A, Richard F, Vessabutr S, Selosse M-A (2009) Two mycoheterotrophic orchids from Thailand tropical dipterocarpacean forests associate with a broad diversity of ectomycorrhizal fungi. BMC Biol 7: 51 doi: 10.1186/1741-7007-7-51.

Shan KC, Liew ECY, Weatherhead MA, Hodgkiss IJ (2002). Characterization and taxonomic placement of Rhizoctonia-like endophytes from orchid roots. Mycologia 94: 230-239.

Stewart SL, Kane ME (2006) Asymbiotic seed germination and in vitro seedling development of Habenaria macroceratitis (Orchidaceae), a rare Florida terrestrial orchid. Pl Cell Tis Organ Cul 86: $147-158$.

Taylor DL, McCormick MK (2007) Internal transcribed spacer primers and sequences for improved characterization of basidomycetous orchid mycorrhizas. New Phytol 177: 1020-1033.

Tremblay RL, Zimmerman JK, Lebrón L, Bayman P, Sastre I, Axelrod F, Alers-García J (1998) Host specificity and low reproductive success in the rare endemic Puerto Rican orchid Lepanthes caritensis. Biol Conser 85: 297-304.

Yoder JA, Imfeld S, Heydinger DJ, Hart CE, Collier MH, Zettler LW (2010) Comparative water balance profiles of Orchidaceae seeds for epiphytic and terrestrial taxa endemic to North America. Pl Ecol 211: 7-17.

Yoder JA, Zettler LW, Stewart SL (2000) Water requirements of terrestrial and epiphytic orchid seeds and seedlings, and evidence for water uptake by means of mycotrophy. Pl Sci 156: 145-150.

Zettler LW, McInnis TM (1992) Propagation of Platanthera integrilabia (Correll) Luer, an endangered terrestrial orchid, through symbiotic seed germination. Lindleyana 7: 154-161.

Zettler LW, Sharma J, Rasmussen F (2003) Mycorrhizal diversity. 
In: Dixon K, Kell SP, Barrett RL, Cribb PJ (eds) Orchid Conservation, Natural History Publications, Kota Kinabalu, Sabah, pp 185-203.

Zettler LW, Stewart SL, Bowles ML, Jacobs KA (2001) Mycorrhizal fungi and cold-assisted symbiotic germination of the Federally threatened eastern prairie fringed orchid, Platanthera leucophaea (Nuttall) Lindley. Am Mid Nat 145: 168-175.

Zettler LW, Wilson Delaney T, Sunley JA (1998) Seed propagation of the epiphytic green-fly orchid (Epidendrum conopseum) using its endophytic fungus. Selbyana 19: 249-253. 